\title{
Comentario a la resolución dictada en el SUP-RAP-58/2013 de la Sala Superior del TEPJF (competencia electoral respecto a las expresiones de los legisladores)
}

\section{Jaime Cárdenas*}

\section{Sumario:}

I. Introducción

II. La importancia político-constitucional del artículo 61 de la Constitución y su relación con la competencia electoral

III. Sobre las responsabilidades parlamentarias y administrativas de los legisladores

IV. Los principios de imparcialidad e igualdad en la aplicación de la ley

V. Conclusiones

* Investigador en el Instituto de Investigaciones Jurídicas de la UNAM. 


\section{Introducción}

El presente análisis comenta la resolución que la Sala Superior del Tribunal Electoral del Poder Judicial de la Federación dictó en el expediente SUP-RAP-58/2013 con motivo del recurso de apelación que el representante del PAN ante el Consejo General del Instituto Federal Electoral presentó en contra de la determinación de ese Consejo del 8 de mayo de 2013, respecto a una queja que previamente el Partido Acción Nacional había instaurado en contra del partido del Trabajo y algunos ex legisladores del grupo parlamentario del Partido del Trabajo en la Cámara de Diputados por hechos que tienen relación con actos acaecidos en sede parlamentaria. En concreto la resolución del Tribunal Electoral aborda el estudio acerca de si la autoridad electoral federal puede iniciar procedimientos de carácter administrativo electoral por manifestaciones realizadas por los legisladores en ejercicio de sus atribuciones en el ámbito de los recintos legislativos, pues las expresiones de los legisladores son inviolables, en los términos de lo previsto en el artículo 61 de la Constitución.

El origen de la resolución de la Sala Superior del Tribunal Electoral del Poder Judicial de la Federación es el siguiente: el 5 de febrero de 2011, el representante suplente del PAN ante el Consejo General del IFE presentó queja en contra del Partido del Trabajo respecto a hechos acontecidos el 3 de febrero de 2011 en la sesión del pleno de la Cámara de Diputados, en donde tres diputados del grupo parlamentario del Partido del Trabajo (Gerardo Fernández Noroña, Jaime Fernando Cárdenas Gracia y Mario Alberto Di Constanzo) se manifestaron en la sesión del pleno con una manta alusiva a Felipe Calderón Hinojosa en la que se contenían expresiones tales como: “ ¿Tú permitirías a un borracho conducir tu auto?”, “¿Entonces por qué lo dejas conducir el país?”. Según el PAN esas expresiones eran calumniosas, groseras y denigratorias con el titular del Ejecutivo Federal y al expresarse en el recinto legislativo interrumpieron el desarrollo de la sesión parlamentaria del 3 de febrero de 2011.

Según la queja del PAN dichas expresiones no podían estar protegidas por el artículo 6o. de la Constitución porque se encontraban en los supuestos de excepción de ese precepto constitucional, implicaron la obstrucción del trabajo legislativo y, que en consecuencia, el Partido 
Esta revista forma parte del acervo de la Biblioteca Jurídica Virtual del Instituto de Investigaciones Jurídicas de la UNAM

del Trabajo había conculcado lo ordenado en el artículos 38, párrafo 1 , incisos $a$ y $b$, del Cofipe por la conducta irregular de los legisladores mencionados en el párrafo anterior. En ese sentido, el representante suplente del PAN ante el Consejo General del IFE solicitaba la investigación de los hechos a efecto de confirmar la conculcación del marco normativo electoral vigente.

Con fecha 15 de noviembre de 2011, el secretario del Consejo General del IFE hizo un requerimiento de información a los otrora legisladores Gerardo Fernández Noroña, Jaime Fernando Cárdenas Gracia y Mario Alberto Di Constanzo para que se contestaran cinco preguntas en torno a la manta exhibida el 3 de febrero de 2011 en la sesión del Pleno de la Cámara de Diputados. A dichas preguntas los legisladores señalados contestaron: 1) que la autoridad electoral violaba lo dispuesto en el artículo 61 de la Constitución porque los legisladores son inviolables por las opiniones que emiten en el desempeño de sus cargos y no pueden jamás ser reconvenidos por ellas; 2) que no existe competencia del IFE para evaluar, conocer o sancionar a los legisladores por sus expresiones; 3 ) que no eran militantes del Partido del Trabajo; 4) que las expresiones emitidas no constituían propaganda político o electoral, y 5) que el IFE estaba vulnerando con su requerimiento y actuación los principios rectores del artículo 41 de la Constitución que lo rigen.

El secretario del Consejo General del IFE radicó con fecha 7 de febrero de 2011 la queja planteada y con fecha 15 de mayo de 2012 ordenó emplazar al Partido del Trabajo. El 21 de mayo de 2012 se contestó la queja por parte del Partido del Trabajo. Se desahogaron las vistas para formular alegatos y, se cerró la instrucción. El 8 de mayo de 2013, el Consejo General del IFE dictó resolución misma que resolvió: Declarar infundado el procedimiento administrativo sancionador respecto del Partido del Trabajo.

Durante el procedimiento ante el IFE, el presidente del Consejo General del IFE, recibió el 24 de noviembre de 2011 oficio firmado por el entonces diputado Emilio Chuayffet Chemor, quien era presidente de la Mesa Directiva de la Cámara de Diputados en el que le precisa respecto a los hechos lo siguiente:

Ningún integrante de esta Soberanía puede ser reconvenido o cuestionado por las expresiones que manifieste, y más aún, cuando estas sean expuestas en el desarrollo de los trabajos legislativos. En tal virtud, con 
Esta revista forma parte del acervo de la Biblioteca Jurídica Virtual del Instituto de Investigaciones Jurídicas de la UNAM

fundamento en el artículo 22 de la Ley Orgánica del Congreso General de los Estados Unidos Mexicanos, la Presidencia de este órgano se pronuncia por el estricto respeto a la protección constitucional de la que gozan las diputadas y diputados que la componen, así como las posiciones políticas que sostengan.

El representante del PAN ante el Consejo General del IFE formuló el 14 de mayo de 2013 recurso de apelación en contra de la resolución del Consejo General del IFE del 8 de mayo de 2013. Los agravios del PAN se hicieron consistir en lo siguiente: 1) que el IFE no había llamado a procedimiento administrativo sancionador ordinario a los legisladores; 2) que el IFE no había realizado una investigación exhaustiva respecto a si los legisladores denunciados eran o no militantes del Partido del Trabajo; 3 ) que no existía una determinación indubitable del IFE sobre si la manta objeto de la denuncia constituía o no propaganda de carácter electoral de carácter calumnioso y ofensivo hacia el titular del Poder Ejecutivo Federal, y 4) que si la autoridad electoral federal no era competente debía dar vista con los hechos a la autoridad competente de la Cámara de Diputados.

Agotado el procedimiento de apelación, el 26 de junio de 2013, la Sala Superior del Tribunal Electoral del Poder Judicial de la Federación dictó su resolución, misma que confirmó lo que ya había determinado el Consejo General del IFE el 8 de mayo del mismo año. La Sala Superior del Tribunal Electoral del Poder Judicial de la Federación desestimó los agravios del PAN, pues consideró que ese partido tenía el deber de controvertir la inviolabilidad de los legisladores por sus expresiones para llamarlos a procedimiento ordinario sancionador electoral y que, sin embargo, el PAN no lo había hecho. La Sala Superior del Tribunal Electoral indicó que el artículo 61 de la Constitución materializa la voluntad del legislador de brindar protección a la libertad, autonomía e independencia de los órganos constitucionales, en específico, de los entonces diputados federales, para impedir que se vea coartada su libertad de expresión, poniéndolos a salvo de cualquier proceso judicial en el cual sean inquiridos por las manifestaciones que realicen en el desempeño de su encargo, cubriendo su participación en actos parlamentarios. En este sentido, los entonces diputados federales estaban protegidos constitucionalmente por el artículo 61 de la carta magna y sus expresiones o manifestaciones realizadas en sede parlamentaria no podían ser objeto de ninguna inquisición o procedimiento administrativo electoral. 
Es importante aclarar que la Sala Superior del Tribunal Electoral del Poder Judicial de la Federación ya había resuelto en los recursos de apelación SUP-RAP 185/2008 y SUP-RAP 187/2008 acumulados, promovidos por los partidos del Trabajo y de la Revolución Democrática, por hechos relacionados con la toma de la tribuna de la Cámara de Diputados por legisladores de esos partidos y con motivo de la reforma energética de 2008, que la conducta de los legisladores se inscribe en el ámbito parlamentario y no electoral, por lo que el IFE carecía de competencia a ese respecto. En la resolución del 7 de noviembre de 2008 la Sala Superior del Tribunal Electoral del Poder Judicial de la Federación no dio vista a la Cámara de Diputados por los hechos relacionados con la toma de la tribuna por parte de los legisladores del Partido del Trabajo y de la Revolución Democrática a la Cámara de Diputados para que se determinara el inicio de algún procedimiento sancionador en sede parlamentaria.

\section{La importancia político-constitucional del artículo 61 de la Constitución y su relación con la competencia electoral}

Los diputados federales son titulares del sufragio pasivo como derecho fundamental reconocido por la Constitución federal (artículos 1o., y 35, fracción II) y los tratados en materia de derechos humanos suscritos por el Estado mexicano: la Declaración Universal de los Derechos Humanos (artículo 21), Pacto Internacional de los Derechos Civiles y Políticos (artículo 25, inciso b), Carta Democrática Interamericana (artículos 2o., 3o., 6o. y 7o.) y la Convención Americana de los Derechos Humanos (artículo 23, inciso b).

El derecho a ser votado o electo a un cargo popular, conforme a la jurisprudencia firme del Tribunal Electoral del Poder Judicial de la Federación número 20/2010 que se identifica con el título Derecho POLÍTICO ELECTORAL A SER VOTADO. INCLUYE EL DERECHO A OCUPAR Y DESEMPEÑAR EL CARGO, comprende en su contenido esencial el "derecho de ejercer las funciones inherentes durante el periodo del encargo", con posibilidad plena para ejercer la libertad de expresión sin que se pueda ser reconvenido por ninguna autoridad por emitir juicios $u$ opiniones. La doctrina ha indicado que el derecho de acceso al cargo 
Esta revista forma parte del acervo de la Biblioteca Jurídica Virtual del Instituto de Investigaciones Jurídicas de la UNAM

público entraña también el derecho a ejercer el mismo con los derechos y privilegios que comporta. ${ }^{1}$

La maximización de la inviolabilidad de expresión y de voto del legislador fortalece al legislador en lo individual y al Congreso en su conjunto. La libre discusión es la base de la función constitucional del legislativo para legislar, criticar, controlar al Ejecutivo y, en síntesis para expresar el pluralismo político. La función legislativa sólo se puede realizar en un clima de libertad sin temor a la represión política o jurídica por las opiniones que se viertan con motivo de la tarea legislativa. Bernardo Bátiz explica que no hay parlamento verdadero sin la vigencia del principio de libertad, tanto jurídica como psicológica o de conciencia. ${ }^{2}$ De esta manera un parlamento para serlo realmente, requiere de plena libertad de sus integrantes para expresar sus opiniones y votos. ${ }^{3}$ Este principio de libertad puede ser considerado en varios niveles y referido al menos a dos sujetos diferentes. Los niveles son el libre albedrío o libertad interior, la libertad física y la libertad jurídica. Los dos sujetos son el cuerpo legislativo y los parlamentarios en lo individual. La libertad del cuerpo colegiado es uno de los presupuestos del Estado constitucional que garantiza la independencia del Legislativo de los demás poderes y de los factores reales de poder. La libertad de los parlamentarios entraña la responsabilidad de decidir de cada uno de los parlamentarios. El legislador debe gozar plenamente de la libertad interior o libre albedrío para escoger entre varias opciones, debe ser, por tanto, maximizada su facultad de razonar, de deliberar y de expresarse. La libertad interior no puede ser suprimida por nada externo al legislador. En cuanto a la libertad física, los legisladores no deben ser impedidos en la toma de decisiones, ni pueden ser usadas en su contra la violencia o la detención arbitraria. La libertad jurídica, por su parte, implica que ninguna reconvención de autoridad puede afectar el curso de las opiniones o votos que adopta el legislador con motivo de su función.

1 Fossas Espadaler, Enric, El derecho de acceso a los cargos públicos, Madrid, Tecnos, 1993, pp. 128 y 129.

2 Bátiz Vázquez, Bernardo, Teoría del derecho parlamentario, Oxford University Press, 1999, pp. 110 y ss.

3 Un estudio detallado sobre los orígenes del voto parlamentario, sus modalidades y consecuencias se encuentra en: Fernández Riveira, Rosa María, El voto parlamentario, Madrid, Centro de Estudios Políticos y Constitucionales, 2003. 
Esta revista forma parte del acervo de la Biblioteca Jurídica Virtual del Instituto de Investigaciones Jurídicas de la UNAM

Desgraciadamente, la historia está plagada de ejemplos de cómo la libertad de los parlamentarios se ha restringido, no sólo con la intervención del Ejecutivo sino se ha coaccionado por el ejército, grupos armados, multitudes vociferantes, y hoy en día, a través de los intereses que representan los factores reales de poder. ${ }^{4}$ En nuestra época de democracia de audiencia, ${ }^{5}$ el legislador también puede ser coaccionado por los medios de comunicación electrónica cuando éstos emprenden una campaña con el propósito de amedrentar y dirigir la actividad legislativa. Existen formas de presión a la libertad de los legisladores más sutiles como el lobbing o el cabildeo, que no siempre consisten en tareas desplegadas para convencer con argumentos y estudios a los legisladores, sino en esquemas que pueden utilizar las amenazas expresas o sobreentendidas en contra de la carrera política de los parlamentarios, o en halagos o promesas de reconocimiento a una carrera política posterior. Sin embargo, lo más grave para la libertad de un legislador, es cuando éste mismo censura su función - por interéspara seguir los dictados de un grupo económico o un medio de comunicación electrónica, para no contradecir a su grupo parlamentario, para no poner en riesgo su carrera personal o sus negocios.

Las interferencias de los partidos y de los grupos parlamentarios en las decisiones del legislador son asunto de todos los días en el órgano legislativo nacional y en los parlamentos del mundo. Bernardo Bátiz, un testigo de privilegio, por el número de veces que ha sido legislador, constata que el fenómeno de la disciplina del voto es una constante, con algunas excepciones notables, y cuando estas últimas se presentan, dan lugar a escisiones partidistas o a sanciones políticas o estatutarias. ${ }^{6} \mathrm{La}$ disciplina partidista puede ser el mecanismo más negativo respecto

${ }^{4}$ Se suelen poner como ejemplos históricos en México, de cómo se ha limitado la libertad de los legisladores, la actitud de Victoriano Huerta, quien después de asesinar a dos legisladores, el diputado Serapio Rendón y el senador Belisario Domínguez, mandó aprehender a todos los integrantes de la Cámara de Diputados de la XXVI Legislatura y disolvió el Congreso mediante decreto presidencial. En época más reciente, y durante 1988, en el debate y votación en el Colegio Electoral de la Cámara de Diputados que declaró válida la elección de Carlos Salinas de Gortari, el ejército rodeó, para amedrentar a los diputados, el recinto parlamentario, situación de la que fue responsable el presidente Miguel de la Madrid y el presidente electo Carlos Salinas de Gortari.

5 Manin, Bernard, Los principios del gobierno representativo, Madrid, Alianza, 1998, pp. 237-287.

6 Bátiz Vázquez, Bernardo, Pido la palabra. Intervenciones legislativas, México, Porrúa, 2005. 
Esta revista forma parte del acervo de la Biblioteca Jurídica Virtual del Instituto de Investigaciones Jurídicas de la UNAM

a la libertad del legislador, y las incompatibilidades debieran regular las formas aceptables, desde un punto de vista democrático, de vinculación entre un legislador y su partido. En muchos países del mundo se establece la prohibición del mandato imperativo, esto es, se rechaza que las "líneas" de los dirigentes partidarios o de los grupos parlamentarios en las sedes legislativas, se impongan por encima de la voluntad y conciencia del legislador y, sin embargo, la disciplina y sujeción permanecen y se afianzan indebidamente y contra el derecho en México y en el mundo.

En nuestro país encontramos que, tanto en el pasado reciente, en donde privaba un partido hegemónico, como en el presente, que se conforma un sistema de partidos de ciertos equilibrios, la presencia de éstos en la vida política es más que evidente. El problema se ha agudizado y hoy los integrantes del Legislativo actúan más como representantes de sus partidos o de las corrientes de los mismos, que como representantes de la sociedad. Desde el punto de vista constitucional la discusión parecería estar resuelta puesto que el artículo 51 de la Constitución señala que los diputados son representantes de la nación, es decir, de acuerdo a la formalidad jurídica los legisladores no representan ni a su distrito ni a su partido ni a su clase social sino a la nación. Los problemas en los hechos subsisten, en la práctica, los legisladores nacionales suelen acatar la disciplina del líder de su bancada, actúan en forma de bloque para debatir y para votar, sus carreras políticas dependen de cómo se guarde la disciplina al interior del grupo parlamentario. Todo lo anterior es muy criticable porque la deliberación parlamentaria, la independencia del órgano sale sobrando cuando los legisladores llegan a los recintos parlamentarios con posiciones que les son impuestas, y que previamente fueron determinadas en las sedes de los partidos o de los grupos parlamentarios. La representación está en crisis, el legislador ya no representa a toda la sociedad, representa en realidad y en contravención a la Constitución a sectores, a grupos sociales o políticos.

En este tenor es fundamental garantizar la prohibición de la reconvención por las opiniones que los legisladores emiten en el desempeño de sus funciones, según lo contempla el artículo 61 de la Constitución, para que el legislador no pueda ser encausado o sancionado ni por sus opiniones ni por sus votos. No debe pasarse por alto que las inviolabilidades e inmunidades son las prerrogativas más importantes 
Esta revista forma parte del acervo de la Biblioteca Jurídica Virtual del Instituto de Investigaciones Jurídicas de la UNAM

de los legisladores ${ }^{7}$ y por ningún motivo deben entenderse como garantías personales sino como garantías funcionales que protegen no la persona del legislador sino la función que éste realiza. Se trata de prerrogativas irrenunciables; en el caso de la inviolabilidad, ni las mismas Cámaras pueden disponer de ella para que se pueda garantizar la independencia y la libertad de los legisladores frente al Ejecutivo, el resto de los poderes formales o los poderes fácticos.

El primer párrafo del artículo 61 de la Constitución que se refiere a las inviolabilidades señala: "Los diputados y senadores son inviolables por sus opiniones manifestadas en el desempeño de sus cargos, y jamás podrán ser reconvenidos por ellas". La inviolabilidad tiene carácter definitivo porque quedan protegidas todas las opiniones vertidas en el desempeño y con motivo del cargo parlamentario y porque sus efectos se prolongan incluso después de haber perdido o concluido la función legislativa. Como dice Eloy García: "La inviolabilidad protege las actuaciones, opiniones o votos emitidos por los parlamentarios en el ejercicio de su mandato, que en ningún caso son o pueden ser constitutivos de delito, falta o cualquier otra infracción legal, impugnable ante sede jurisdiccional alguna".

En México, la Primera Sala de la Suprema Corte de Justicia de la Nación, en el amparo en revisión 2214/98, del 24 de mayo de 2000, determinó que los legisladores jamás podrán ser reconvenidos por las opiniones que manifiesten en el desempeño de sus cargos y que en esa tesitura, no proceden acciones civiles por daño moral en donde la causa de pedir sean expresiones de los legisladores realizadas como motivo de su encargo. Por su parte, en la resolución del 22 de febrero de 2010, en el amparo en revisión 27/2009, el pleno de la Suprema Corte de Justicia de la Nación, determinó que la inviolabilidad parlamentaria prevista en el artículo 61 de la Constitución, sólo protege al legislador por expresiones que emite con motivo de sus funciones legislativas y no respecto de otras que no tienen relación con el encar-

7 Otras de las prerrogativas tienen que ver con el derecho a recibir la dieta correspondiente, lo que deriva de los artículos 36 fracción IV, 64 y 127 de la Constitución. La dieta es irrenunciable. Un estudio que analiza el marco jurídico de las retribuciones de los parlamentarios es el de: Jiménez Aparicio, Emilio, Régimen jurídico de las retribuciones de los diputados y senadores, Madrid, Centro de Estudios Constitucionales, 1994.

${ }^{8}$ García, Eloy, Inmunidad parlamentaria y Estado de Partidos, Madrid, Tecnos, 1989, p. 64 . 
Esta revista forma parte del acervo de la Biblioteca Jurídica Virtual del Instituto de Investigaciones Jurídicas de la UNAM

go. ${ }^{9}$ Más recientemente, en el amparo directo en revisión 284/2011, (recurrente Germán Martínez Cázares) la Primera Sala de la Suprema Corte de Justicia de la Nación señaló respecto a afirmaciones del otrora diputado Germán Martínez Cázares que imputó en sede no parlamentaria al licenciado Manuel Bartlett Díaz que era el "artífice del fraude electoral” y el "presunto asesino de Manuel Buendía”, que al recurrente "... no le es exigible el requisito de veracidad... pues sus manifestaciones se encuentran protegidas constitucionalmente al haber ejercido su libertad de expresión, dentro del debate político.... ${ }^{10}$

El sentido que tiene la inviolabilidad del legislador en sus opiniones y votos es para que exista mayor participación ciudadana, más deliberación en los asuntos públicos, más publicidad en el funcionamiento de cualquier estructura relevante de la sociedad o del Estado, más controles independientes y también más controles de la sociedad civil a los partidos y a otros factores reales de poder, pues sin medidas como las anteriores, la inviolabilidad del primer párrafo del artículo 61 de la Constitución puede ser una norma vacía de contenidos.

Lo anterior significa que no es constitucional censurar a los legisladores por sus expresiones, ni de manera directa ni de forma oblicua. El Tribunal Electoral no podía poner por encima de la Constitución una obligación legal que es para los partidos (el artículo 38.1, inciso $b$, del Cofipe) y no para los legisladores, sobre el contenido de principios constitucionales - los artículos 6o. y 61 de la Constitución- que protegen no sólo la libertad e independencia de uno o varios legisladores sino de todo el Congreso en su conjunto. Haber actuado prefiriendo la ley a Constitución, implicaba una transgresión constitucional que no puede ser tolerada en un Estado constitucional y democrático de derecho.

9 Esta decisión se produjo a consecuencia del amparo directo promovido por Manuel Bartlett Díaz en contra de la sentencia del 12 de agosto de 2008 dictada por la décima sala civil del Tribunal Superior de Justicia. Bartlett había demandado por la vía civil la reparación del daño moral a Germán Martínez Cázares, en ese entonces diputado federal, por expresiones que había emitido como representante del PAN en el Consejo General del IFE, durante el proceso electoral federal de 2006.

10 Amparo directo en revisión 284/2011, recurrente Germán Martínez Cázares, resolución del 21 de noviembre de 2012. Primera Sala de la Suprema Corte de Justicia de la Nación. Ponente: ministra Olga Sánchez Cordero de García, p. 126. 
Esta revista forma parte del acervo de la Biblioteca Jurídica Virtual del Instituto de Investigaciones Jurídicas de la UNAM

La Sala Superior del Tribunal Electoral del Poder Judicial de la Federación tomó en cuenta en su resolución y para normar su criterio, los siguientes elementos:

1) Los legisladores denunciados por el PAN ejercieron una función legislativa y parlamentaria - la función expresiva según lo expone Walter Bagehot en La Constitución inglesa- ${ }^{11}$ para exponer no sólo los rumores en torno al presunto alcoholismo de Felipe Calderón sino para criticar la conducción política de su gobierno. Tal como se hizo constar en el Diario de Debates de la Cámara de Diputados del 8 de febrero de 2011 que continuó el debate del 3 de febrero de 2011 en torno a los hechos.

2) El artículo 6o. de la Constitución reconoce los derechos de libertad de expresión y el principio de máxima publicidad. La Primera Sala de la Suprema Corte indicó en el amparo directo en revisión 284/2011, (recurrente Germán Martínez Cázares) respecto a afirmaciones del otrora diputado Germán Martínez Cázares que imputó en sede no parlamentaria la licenciado Manuel Bartlett Díaz que era el "artífice del fraude electoral" y el "presunto asesino de Manuel Buendía”, que al recurrente “... no le es exigible el requisito de veracidad... pues sus manifestaciones se encuentran protegidas constitucionalmente al haber ejercido su libertad de expresión, dentro del debate político...." ${ }^{2}$

3) El artículo 61 de la Constitución protege la inviolabilidad de los legisladores por sus opiniones en el ejercicio de sus cargos y jamás pueden ser reconvenidos por ellas.

4) Los legisladores expresaron sus puntos de vista en una sesión del Pleno de la Cámara de Diputados — la del 3 de febrero de 2011sobre un asunto de carácter nacional relacionado con el presunto alcoholismo del titular del Ejecutivo en relación con la conducción política que realizaba del país.

5) No existe constancia alguna que los legisladores hayan tomado la tribuna de la Cámara de Diputados, es decir, el espacio que ocupa el legislador en turno para exponer sus puntos de vista, jamás

11 Bagehot, Walter, La Constitución inglesa, México, UNAM, 2005, p. 136

12 Amparo directo en revisión 284/2011, recurrente Germán Martínez Cázares, resolución de 21 de noviembre de 2012. Primera Sala de la Suprema Corte de Justicia de la Nación. Ponente: Ministra Olga Sánchez Cordero de García, página 126. 
se apoderaron de los micrófonos ni ocuparon los espacios de la Presidencia o de la Secretaría de la Mesa Directiva de la Cámara de Diputados. Sólo se expresaron con una manta y se colocaron enfrente del recinto parlamentario. La sesión del Pleno de la Cámara de Diputados del 3 de febrero de 2011 se suspendió por decisión de la Presidencia de la Mesa Directiva de esa Cámara ante las reacciones de los diputados del grupo parlamentario del PAN. El presidente de la Mesa consideró que no existían condiciones para continuar con la sesión.

6) No existe relación de causalidad, causa-efecto, de carácter necesario entre exponer un punto de vista en un recinto parlamentario, por más que sea, según el juicio de algunos, equivocado, incorrecto o falso, con la obstrucción o el impedimento en el funcionamiento regular de un órgano de gobierno de alguna de las Cámaras. Sostener un punto de vista así nos conduce a la falacia de la falsa causa que consiste en establecer como causa de un efecto, una causa que no tiene relación directa con las consecuencias o efectos. En otras palabras, no siempre que se exponen puntos de vista duros o fuertes en los recintos parlamentarios se obstaculiza o se impide el desarrollo de las sesiones. El Congreso es, para entre otras cosas, deliberar fuerte y duro.

En la falacia de la causa falsa se trata como causa de un fenómeno algo que en realidad no es su causa. No siempre la mera sucesión temporal entre hechos o fenómenos establece una conexión causal entre ellos. Una de las variedades de la falacia de la causa falsa es la que se conoce como "Post hoc, ergo propter hoc" (después de esto, por lo tanto, debido a esto) que implica asumir la causalidad demasiado pronto sobre la base de la mera sucesión en el tiempo. ${ }^{13}$

La falacia de la falsa causa puede ocurrir por lo siguiente: 1) se toma al antecedente o lo concomitante confundiéndolo con la causa, es así que en ocasiones, se toma al error o al miedo como antecedente del negocio jurídico, cuando en realidad son la causa; 2) considerar como causa de un hecho un acontecimiento que simplemente dio ocasión a él como en este caso, y 3) tomar por

\footnotetext{
13 Weston, Anthony, Las claves de la argumentación, Barcelona, Ariel, 1998, p. 133.
} 
Esta revista forma parte del acervo de la Biblioteca Jurídica Virtual del Instituto de Investigaciones Jurídicas de la UNAM

causa lo que solamente es condición (una estancia iluminada tiene por causa el sol y por condición el estar abierta la ventana). ${ }^{14}$

Tron Petit propone el siguiente ejemplo de la falacia de la falsa causa:

Supóngase que la autoridad niega la devolución de un impuesto y se aduce como violación el no haberse aplicado determinada jurisprudencia sobre inconstitucionalidad; cuando que, la causa auténtica, es que el quejoso no probó que el pago efectuado hubiese sido indebido, en tanto consintió la ley base del adeudo y voluntariamente lo enteró, sin que le beneficie la jurisprudencia invocada, dado el principio de relatividad, ya que no promovió, en su oportunidad, juicio de amparo. ${ }^{15}$

7) La vida parlamentaria no puede ser evaluada en los recintos de los plenos y comisiones del Congreso de la Unión y en tratándose de libertad de expresión con criterios administrativos, susceptibles de ser motivo de responsabilidades administrativas, porque en ese momento se acabaría con la libertad e independencia de los legisladores y del propio Congreso. Sería el fin de la deliberación pública y política.

8) Las inviolabilidades son las prerrogativas más importantes de los legisladores ${ }^{16}$ y por ningún motivo deben entenderse como garantías personales sino como garantías funcionales que protegen no la persona del legislador sino la función que éste realiza. Se trata de prerrogativas irrenunciables; en el caso de la inviolabilidad, ni las mismas Cámaras pueden disponer de ella para que se pueda garantizar la independencia y la libertad del legislador frente al Ejecutivo, el resto de los poderes formales o los poderes fácticos.

${ }_{14}$ Mans Puigarnau, Jaime M., Lógica para juristas, Barcelona, Bosch, 1978, pp. 216 y 217.

15 Tron Petit, Jean Claude, Argumentación en el amparo. Esquema formal de los conceptos de violación y las sentencias de amparo, México, Porrúa, 2010, p. 38.

16 Otras de las prerrogativas tienen que ver con el derecho a recibir la dieta correspondiente, lo que deriva de los artículos 36 fracción IV, 64 y 127 de la Constitución. La dieta es irrenunciable. Un estudio que analiza el marco jurídico de las retribuciones de los parlamentarios es el de: Jiménez Aparicio, Emilio, Régimen jurídico de las retribuciones de los diputados y senadores, Madrid, Centro de Estudios Constitucionales, 1994. 
De acuerdo a la reciente reforma a la Constitución en materia de derechos humanos, publicada en el Diario Oficial de la Federación el 10 de junio del 2011, las normas sobre derechos humanos deben interpretarse de conformidad con la Constitución y los tratados favoreciendo en todo tiempo a las personas la protección más amplia. En este sentido, la Sala Superior del Tribunal Electoral del Poder Judicial de la Federación maximizó el derecho a ser votado en su vertiente a ejercer de manera plena y libre la función de diputado federal y, concluyó que no era dable transgredir los artículos 6o. y 61 de la Constitución con el inicio de procedimiento ordinario sancionador electoral o, de otro tipo, en contra de los legisladores.

\section{Sobre las responsabilidades parlamentarias y administrativas de los legisladores}

Los diputados federales como titulares del derecho a ejercer las funciones inherentes al cargo popular tienen el derecho a participar directamente en los asuntos públicos como representantes libremente elegidos, tal como lo reconoce la Declaración Universal de los Derechos Humanos (artículo 21), el Pacto Internacional de los Derechos Civiles y Políticos (artículo 25, inciso b), laCarta Democrática Interamericana (artículos 2o., 3o., 6o. y 7o.) y la Convención Americana de los Derechos Humanos (artículo 23, inciso $b$ ), en específico tienen derecho a participar con libertad e independencia en sede parlamentaria en cualquier debate político, sin que por el ejercicio de la libertad de expresión sean reconvenidos directa, indirectamente o de manera oblicua.

El PAN en su apelación estimó que si el IFE no conocía de los hechos, la Cámara de Diputados tendría que conocer de los mismos y, en su caso, determinar si el actuar de los legisladores contravino alguna disposición constitucional o legal. Tal pretensión desconoce la naturaleza de los actos parlamentarios.

Según muchísimos doctrinarios —empezando por Bagehot y terminando con Andrea Manzella- ${ }^{17}$ que sostienen que la deliberación,

17 Bagehot, Walter, La Constitución inglesa, México, UNAM, 2005, p. 136, y Manzella, Andrea, El Parlamento, México, Instituto de Investigaciones Legislativas, 1987, pp. 173 y ss. 
Esta revista forma parte del acervo de la Biblioteca Jurídica Virtual del Instituto de Investigaciones Jurídicas de la UNAM

la libre expresión, la libre discusión y el debate, son elementos básicos para la existencia del Parlamento, al igual que las garantías de los legisladores para propiciar esa amplia deliberación. Se trata de una función esencial y consustancial al Parlamento. Reducirla, perseguirla, reconvenirla o sancionarla, de manera directa, indirecta u oblicua, implica trastocar el sentido democrático del Parlamento.

$\mathrm{Ni}$ formal ni materialmente las expresiones que realizan los legisladores en sede parlamentaria pueden quedar comprendidas dentro de los actos administrativos. El PAN tiene un problema grave con la calificación de los hechos, tal como lo señalaría Neil MacCormick. ${ }^{18}$ $\mathrm{Ni}$ siquiera fueron expresiones en torno a los recursos materiales, humanos o financieros de la Cámara o actos de los legisladores que desviaran recursos públicos. Son conductas que no caben, que no se encuentran comprendidas en las diversas hipótesis del artículo 8o. de la Ley Federal de Responsabilidades Administrativas de los Servidores Públicos. El PAN pretendía que los legisladores no tengan inviolabilidad por sus expresiones y, que si éstas de alguna forma implican la afectación a los trabajos de las Cámaras, entonces deben ser sometidos a procedimientos de responsabilidades administrativas.

La reglamentación de la Cámara de Diputados que estaba vigente al momento de los hechos es el Reglamento de la Cámara de Diputados que entró en vigor el primero de enero de 2011. El artículo 260 de ese Reglamento señala que el presidente de la Mesa Directiva de la Cámara en el desarrollo de las sesiones para inhibir la interrupción o afectación de las discusiones y decisiones parlamentarias puede adoptar entre otras, por acciones como las siguientes: llamar al orden, declaración de falta de orden con mención en el acta, retiro del sonido, dictar otras medidas para mantener el orden, retiro de expresiones materiales (las mantas), etcétera. Es decir, el ordenamiento jurídico nacional en materia de orden en las sesiones del Pleno y de las comisiones de la Cámara de Diputados establece vías parlamentarias — no vías de responsabilidad administrativa - para lograr la discusión, deliberación y aprobación de las decisiones parlamentarias. Las vías parlamentarias, según el artículo 260 del Reglamento de la Cámara de Diputados, se deben emplear sesión a sesión, lo que significa que no son susceptibles de aplicarse cuando la sesión correspondiente ha concluido. Ja-

${ }_{18}$ MacCormick, Neil, Legal Reasoning and Legal Theory, Oxford University Press, 1978, pp. 97 y ss. 
más al legislador de nuestro país se le ha ocurrido tratar los temas de orden en los recintos parlamentarios como si fuesen asuntos de orden administrativo o de indisciplina administrativa. Las Cámaras son asambleas de pares, en donde uno de los legisladores, el presidente de la Mesa, conduce las sesiones y los debates y, aplica reglas para favorecer el debate, no para sancionar administrativamente con facultades de imperio al resto de sus pares cuando éstos a su juicio se extralimitan en sus funciones. La finalidad de los reglamentos parlamentarios es volver a reconducir la discusión cuando existe algún incidente que pone en riesgo la discusión, la deliberación o la decisión parlamentaria. La finalidad no es sancionar administrativamente y mucho menos penalmente a los legisladores por sus expresiones.

La pretensión de que sea el contralor de la Cámara de Diputados el que sancione a un legislador por sus expresiones o por las remotas consecuencias de éstas, es desafortunada, por dos razones: 1) la Contraloría es un órgano subordinado al Pleno de la Cámara de Diputados, nombrado por el Pleno de la Cámara — cómo va a conocer y juzgar una instancia subordinada a alguien que lo ha nombrado-; 2) si el contralor de la Cámara de Diputados pudiera conocer y juzgar en torno a las expresiones y deliberaciones de los legisladores entonces el contralor sería el auténtico poder legislativo en México y no los plenos, las comisiones y los mismos legisladores del Congreso de la Unión.

Finalmente, la deliberación en una asamblea tiene características diversas a las de una deliberación en un tribunal o en sede administrativa. El PAN tendría que reconocer al menos las características deliberativas de cada género oratorio en cada ámbito y encontrar las especificidades de la deliberación parlamentaria que están determinadas, principalmente por el principio de inviolabilidad de las opiniones de los legisladores, ese principio es la base, el fundamento de los Parlamentos que se precian de democráticos.

\section{Los principios de imparcialidad e igualdad en la aplicación de la ley}

La Sala Superior del Tribunal Electoral del Poder Judicial de la Federación salvaguardó en este caso los principios de imparcialidad y 
Esta revista forma parte del acervo de la Biblioteca Jurídica Virtual del Instituto de Investigaciones Jurídicas de la UNAM

de igualdad en la aplicación de la ley porque ante casos semejantes - los que conoció la Sala Superior del Tribunal Electoral del Poder Judicial de la Federación el 7 de noviembre de 2008 en los recursos de apelación SUP-RAP 185/2008 y SUP/RAP 187/2008 - aplicó criterios análogos. En la resolución del 7 de noviembre de 2008 la Sala Superior del Tribunal Electoral del Poder Judicial de la Federación no dio vista por los hechos relacionados con la toma de la tribuna por parte de los legisladores del Partido del Trabajo y de la Revolución Democrática a la Cámara de Diputados para que se determinara el inicio de algún procedimiento sancionador.

Como se sabe, una de las facetas de la imparcialidad es resolver casos similares con criterios análogos para que no exista desigualdad en la aplicación de las normas. Si en la ocasión anterior, derivada de la resolución de la Sala Superior del Tribunal Electoral del Poder Judicial de la Federación, del 7 de noviembre de 2008, dictada en los recursos de apelación SUP-RAP 185/2008 y SUP/RAP 187/2008, el Consejo General del IFE no dio vista a la Cámara de Diputados, por qué en esta ocasión tendría que dar vista como pretendía el PAN. El apelante no logró explicar por qué este caso es distinto al anterior.

La finalidad de los precedentes es preservar los principios de igualdad en la aplicación de la ley y, el de justicia uniforme o principio de universalidad o de imparcialidad. El criterio de igualdad en la aplicación de la ley obliga a que el mismo órgano no pueda modificar arbitrariamente el sentido de sus decisiones en casos sustancialmente iguales y que cuando el órgano en cuestión considere que debe apartarse de sus precedentes tiene que ofrecer para ello una fundamentación suficiente y razonable. ${ }^{19}$ El precedente se proyecta hacia el pasado y hacia el futuro. Hacia el pasado porque se obliga al órgano a resolver los casos del mismo modo en que haya resuelto otros casos similares $y$, hacia el futuro, porque obliga al órgano a usar el criterio establecido en casos futuros de naturaleza similar. ${ }^{20}$

Las autoridades deben vincularse a los precedentes para salvaguardar los principios de igualdad en la aplicación de la ley y el principio de universalidad o imparcialidad. Cuando se aparten del propio pre-

19 Ollero, Andrés, Igualdad en la aplicación de la ley y precedente judicial, Madrid, Centro de Estudios Políticos y Constitucionales, 2005, pp. 23 y ss.

${ }_{20}$ Maccormick, Neil, Legal Reasoning and Legal Theory, Oxford, Clarendon Press, 1978, p. 97. 
cedente, porque se estime que ya no es correcto o porque las circunstancias se han modificado, están obligados a justificarlo mediante la elaboración de otro criterio que cumpla con el requisito de universalización -que sea susceptible de aplicarse a otros casos futuros de naturaleza similar-.

\section{Conclusiones}

La resolución que comentamos de la Sala Superior del Tribunal Electoral del Poder Judicial de la Federación pone en evidencia la trascendencia de la inviolabilidad parlamentaria. La inviolabilidad tiene carácter definitivo porque quedan protegidas todas las opiniones vertidas en el desempeño y con motivo del cargo parlamentario y porque sus efectos se prolongan incluso después de haber perdido o concluido la función legislativa. Como dice Eloy García, la inviolabilidad protege las actuaciones, opiniones o votos emitidos por los parlamentarios en el ejercicio de su mandato, que en ningún caso son o pueden ser constitutivos de delito, falta o cualquier otra infracción legal, impugnable ante sede jurisdiccional alguna.

En México, la Primera Sala de la Suprema Corte de Justicia de la Nación, en el amparo en revisión 2214/98, del 24 de mayo de 2000, determinó que los legisladores jamás podrán ser reconvenidos por las opiniones que manifiesten en el desempeño de sus cargos y que en esa tesitura, no proceden acciones civiles por daño moral en donde la causa de pedir sean expresiones de los legisladores realizadas como motivo de su encargo. Por su parte, en la resolución del 22 de febrero de 2010, en el amparo en revisión 27/2009, el pleno de la Suprema Corte de Justicia de la Nación, determinó que la inviolabilidad parlamentaria prevista en el artículo 61 de la Constitución, sólo protege al legislador por expresiones que emite con motivo de sus funciones legislativas y no respecto de otras que no tienen relación con el encargo. Más recientemente, en el amparo directo en revisión 284/2011 (recurrente Germán Martínez Cázares), la Primera Sala de la Suprema Corte de Justicia de la Nación señaló respecto a afirmaciones del otrora diputado Germán Martínez Cázares, el que imputó en sede no parlamentaria al licenciado Manuel Bartlett Díaz de ser el "artífice del fraude electoral” y el "presunto asesino de Manuel Buendía”, que al 
recurrente, es decir, a Germán Martínez “... no le es exigible el requisito de veracidad... pues sus manifestaciones se encuentran protegidas constitucionalmente al haber ejercido su libertad de expresión, dentro del debate político...”.

La vista a la Cámara de Diputados que proponía el PAN para que en sede parlamentaria los legisladores fueran sometidos a un procedimiento de responsabilidad administrativa implicaba una forma oblicua e indirecta de reconvención a las opiniones de los legisladores, una manera de limitar la libertad de expresión de los legisladores cuando éstos emiten sus opiniones en sede parlamentaria y con motivo de sus funciones. Los artículos 6o. y 61 de la Constitución protegen no sólo la libertad e independencia de uno o varios legisladores sino de todo el Congreso en su conjunto.

En la resolución en estudio de la Sala Superior del Tribunal Electoral del Poder Judicial de la Federación, los principios de imparcialidad y de igualdad en la aplicación de la ley fueron salvaguardados, porque ante casos semejantes - los SUP-RAP 185/2008 y SUP-RAP 187/2008 dictados con motivo de la toma de tribuna de la Cámara de Diputados en protesta con la reforma energética de 2008- el Tribunal resolvió de manera análoga. En la resolución del 7 de noviembre de 2008 el Tribunal Electoral no dio vista a la Cámara de Diputados, ni el IFE lo hizo para que se continuara en sede parlamentaria un procedimiento de responsabilidad administrativa en contra de los legisladores que habían tomado la tribuna de la Cámara de Diputados con motivo de la reforma energética de 2008. 